Alma Mater Studiorum - Università di Bologna DEPARTMENT OF ECONOMICS

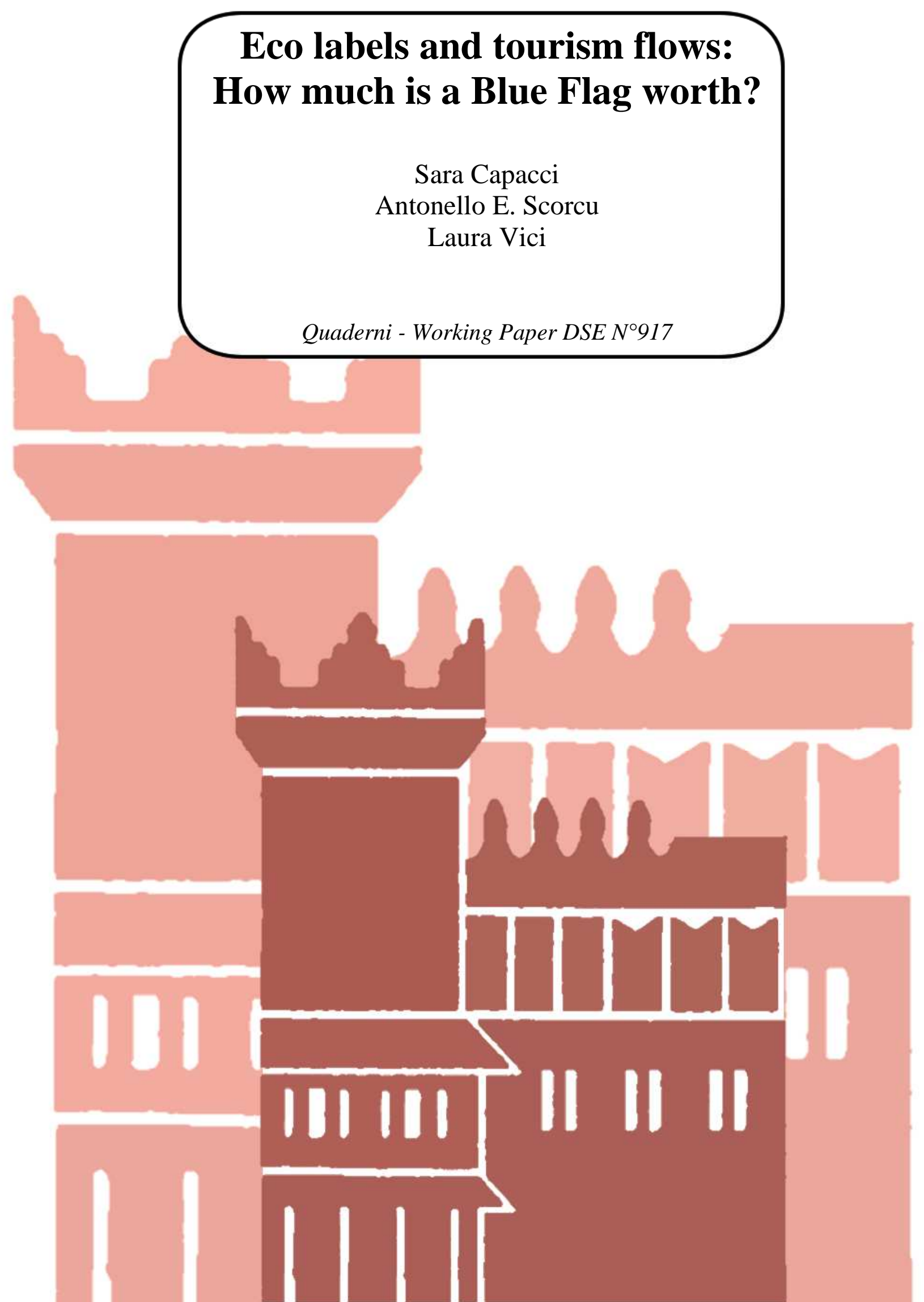




\title{
Eco labels and tourism flows: How much is a Blue Flag worth?
}

\author{
Sara Capacci* $\quad$ Antonello E. Scorcu ${ }^{\dagger} \quad$ Laura Vici ${ }^{\star}$ \\ Department of Economics, University of Bologna
}

January 9, 2014

\begin{abstract}
The rise in destination accessibility and the emergence of new market segments have increased the competition among tourism destinations, both at national and international level. In order to gain a significant competitive advantage over competitors, destinations increasingly make use of signals that certify and communicate the level of quality provided. While existing research on tourism certifications mostly pertains to quality evaluation, this study exploits quantitative methods to assess the economic impact of destinations' labels. The analysis considers one of the most popular certification of environmental quality attributed to beaches, the Blue Flag award. It explores the relationship between the certification achievement and inbound tourist flows, focusing on the Italian case study. In fact, given their aim of providing synthetized information on destinations, certification programs particularly affect foreign tourists who suffer more from asymmetric information. Panel data techniques and highly disaggregated data are employed to compare the attractiveness of certified and non-certified provinces, by controlling for several factors potentially confounding the effect of the certification.
\end{abstract}

Keywords: international tourism flows; ecolabel; dynamic panel model; Italy. JEL codes: C23; L83; Z12

\footnotetext{
* Sara Capacci (corresponding author) Department of Economics, University of Bologna, Strada Maggiore 45, 40125 Bologna, Italy. Email: sara.capacci@unibo.it

$\uparrow$ Antonello E. Scorcu Department of Economics, University of Bologna, Strada Maggiore 45, 40125 Bologna, Italy. Email: antonello.scorcu@unibo.it

* Laura Vici. Department of Economics, University of Bologna, Strada Maggiore 45, 40125 Bologna, Italy. Email: laura.vici@unibo.it
} 
Tourism is one of the most important industries in Italy. In 2012 its direct contribution to total GDP amounted to 81.9 billion US\$ (4.2\% of total GDP), largely above the world average of 17.2 US\$ billions (WTTC, 2012). Although the largest part of its tourism demand is related to domestic tourism, Italy is the sixth most visited country in the world, having approximately attracted 44.4 million of international tourist arrivals in 2013 (WTTC, 2013). Yet, the dramatic reduction in transportation costs and time, the simultaneous increase in travel comforts, the advent of new tourist segments and new tourist destinations have introduced deep changes in the tourism sector. These are likely to threaten the Italian leadership, also in the field of seaside tourism, which is one of the most important segments of Italian tourism market. Competition among seaside destinations takes place both at the national and international level and tourism firms are increasingly focused at gaining significant competitive advantage over competitors. Rejuvenation strategies are therefore developed in order to gain or retain some market power over domestic or international competitors, with positive effects on revenues, arrivals and overnight stays. A crucial part of this complex and multifaceted strategy is the signaling of high (tourist) quality, through strong, credible, externally certified quality signals.

In particular, in a period of rising environmental concern and awareness, environmental certifications (ecolabels) are employed to promote tourist destinations and increase their competitiveness. Although the great emphasis given by the media and the flourishing of quality studies on environmental certifications, quantitative estimations of their economic impact are almost missing (see Section 3).

In order to fill this gap, the present work considers one of the most popular ecolabel in seaside tourism, the Blue Flag award, and explores the relationship between the certification achievement and tourist flows, focusing on the Italian case study. Given their purpose of providing synthetized information on destinations, we expect that certification programs might particularly affect foreign tourists who mostly suffer from asymmetric information on tourism destinations. Moreover, foreign tourists' choices are more likely affected by destination attractions whereas domestic flows are often driven by non-tourist factors such as geographic proximity or periodical family visits which confer persistency to travels. Thus, our analysis aims at assessing the effectiveness of environmental accreditation attributed to beaches in attracting foreign tourists to Italian coasts. Panel data techniques are employed to compare the attractiveness of certified and non-certified provinces, by implicitly controlling for all the factors potentially confounding the effect of the certification. We adopt dynamic specifications in order to account for persistency and reputation effects in tourism. Moreover, the analysis - based on provincial data - focuses exclusively on seaside inbound tourism, disentangled from total inbound flows. This represents a key innovation with respect to existing studies on the topic, which refer to overall regional or provincial flows, irrespective of its seaside or non-seaside nature (Quintiliani, 2009; Marrocu and Paci, 2013). Having provided a robust estimate of the label effectiveness in attracting foreign tourists, we will show how the estimate is affected by the inclusion in the analysis of non-seaside tourism. 
The rest of the paper is organized as follows. Section 2 briefly introduces the Blue Flag certification program and the diffusion of the ecolabel among Italian seaside destinations. Section 3 surveys existing studies assessing the impact of quality certification on tourism. Section 4 details the model employed and the econometric methods used for estimation. A description of the data sources is included. Section 5 reports the empirical results. Concluding remarks are summarized in Section 6.

\section{Blue Flag destinations and tourism flows to Italian coasts}

Environmental certification programs define, test and summarize the multiple dimensions of environmental quality of tourism products into easy and readable codes. This has the effect of promoting and awarding good practices among local public authorities and tourist sector operators. Moreover, this increases the level of information about tourism destinations, which is often asymmetric, especially for foreign consumers. Providing more reliable information might attract otherwise discouraged tourists who might lack sufficient knowledge on destinations. In addition, ecolabels might beckon new market segments, namely those characterized by sensitiveness to environmental issues.

The Blue Flag (BF) is bestowed to beaches and marinas of 48 countries in the world by the Danish Foundation of Environmental Education. The label is awarded to destinations that meet 32 criteria concerning water quality, environmental management of the sites, environmental education and information, and beach services ${ }^{1}$. Thus, fulfilling the quality standards implies relevant costs both for local authorities and for beach operators, who are highly interested in quantifying the economic return of these practices.

Nowadays, the Blue Flag is considered as a symbol of quality recognized by tourists and tour operators around the world. In 2013, 3850 beaches and marinas were awarded with the label throughout the world. Every year more than 200 labels are assigned to Italian beaches².

Table 1 summarizes the distribution of the labels across Italian littoral regions in 2012 and in the period 2000-2012. According to the Table, neither the littoral nature of an area (proxied by the number of littoral municipalities) nor its accommodation capacity seems to explain univocally the BF geographic distribution. In fact, the regions with the highest number of coastal municipalities (Sicily, Calabria and Sardinia) have recorded a

\footnotetext{
${ }^{1}$ Inclusion criteria comprise the following: waste-water or sewage-related discharges should not affect the beach area, facilities for the separation of recyclable waste materials should be available at the beach, an adequate number of toilet or restroom facilities must be provided, the toilet or restroom facilities must have controlled sewage disposal, environmental education activities must be offered and promoted to beach users, information about bathing water quality must be displayed, safety measures, wheelchair access and accessibility features must be in place.

${ }^{2}$ Despite Blue Flags are assigned also to lake shores and marinas, the present work focuses exclusively on seaside beaches. Although the label is attributed to delimited segments of shoreline, local authorities and the media very often refer to the certification as if pertaining to the overall seaside area belonging to a given municipality. Moreover, data on the BF attribution are provided by municipality.
} 
limited number of Blue Flags in the last 13 years, as compared with other areas with fewer littoral municipalities (see Liguria, Tuscany and Marche). Yet, if for some regions a broad accommodation capacity matches with a high number of labels, this is not always true ${ }^{3}$.

Table 1 Blue Flags distribution among coastal regions in Italy.

\begin{tabular}{|c|c|c|c|c|}
\hline Coastal Regions & $\begin{array}{c}\text { Num. of coastal } \\
\text { Municipalities per Region }\end{array}$ & $\begin{array}{l}\text { Accommodation } \\
\text { capacity }(\%)^{\mathrm{a}}\end{array}$ & $\begin{array}{l}\text { Num. of BF } \\
\text { in } 2012\end{array}$ & $\begin{array}{l}\text { Total num. of BF in the } \\
\text { period 2000-12 }\end{array}$ \\
\hline Liguria & 63 & 3.5 & 18 & 172 \\
\hline Tuscany & 35 & 11.7 & 16 & 170 \\
\hline Marche & 23 & 4.4 & 16 & 161 \\
\hline Abruzzo & 19 & 2.5 & 13 & 134 \\
\hline Campania & 60 & 2.6 & 13 & 120 \\
\hline Emilia-Romagna & 14 & 9.9 & 8 & 104 \\
\hline Apulia & 67 & 5.6 & 10 & 88 \\
\hline Sicily & 122 & 4.4 & 5 & 51 \\
\hline Veneto & 11 & 15.9 & 6 & 49 \\
\hline Calabria & 116 & 2.5 & 5 & 47 \\
\hline Lazio & 24 & 6.7 & 5 & 47 \\
\hline Sardinia & 71 & 4.6 & 6 & 37 \\
\hline Friuli-Venezia Giulia & 9 & 1.0 & 2 & 26 \\
\hline Basilicata & 7 & 0.9 & 1 & 21 \\
\hline Molise & 4 & 0.3 & 2 & 16 \\
\hline
\end{tabular}

${ }^{a}$ Bed places in hotels and other accommodation establishments, expressed as \% of the total Italian capacity Source: Italian National Institute of Statistics (ISTAT) and the Blue Flag Program (http://www.bandierablu.org)

Figure 1 depicts the label distribution by province. A comparison of 2000 and 2012 shows how Italian coasts have become bluer in the last 13 years, since the number of certifications has increased from 73 to 131 (Figure A1 in the Appendix reports yearly maps for the overall period).

${ }^{3}$ In 2012, the correlation between the number of Blue Flags and the number of coastal municipalities in each province is slightly positive but not statistically significant $(0.1934)$. This result is confirmed over time. 
Figure 1. Geographic distribution of the Blue Flags among Italian coastal provinces, years 2000 and 2012.
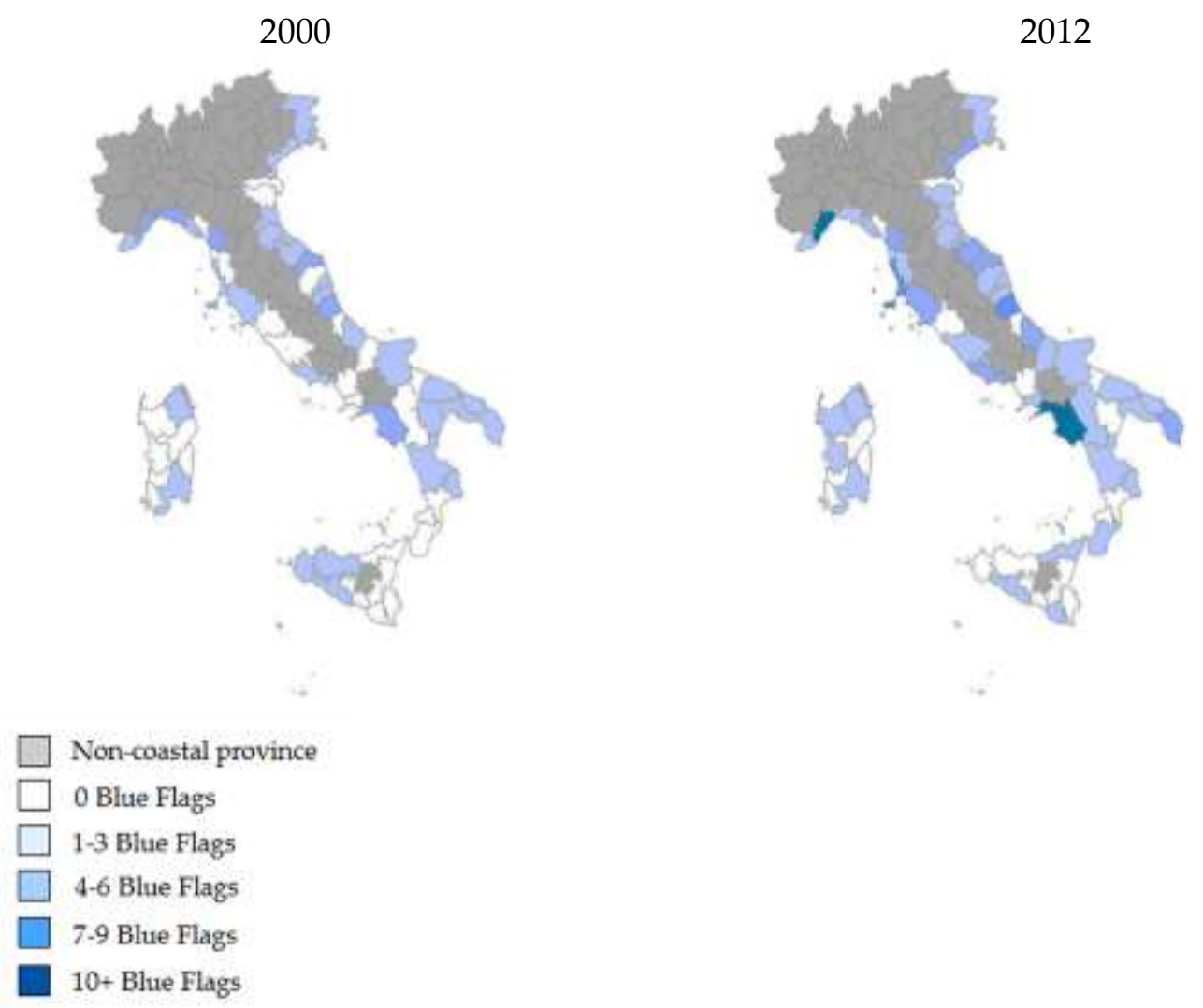

Source: the Blue Flag Program (http://www.bandierablu.org)

With regard to the overall internal tourism, Table 2 returns a picture of the composition of the Italian tourism market. In 2011 seaside destinations attracted the most relevant portion of tourism flows measured in terms of overnight stays ( $31 \%$ of total flows). If the number of arrivals is considered, beach and sun destinations come after cultural heritage sites (covering respectively $22 \%$ and $36 \%$ of total arrivals), revealing different average length of stay for the two types of tourism.

Table 2 Overall internal tourism, by type of destination, 2011.

\begin{tabular}{lcc}
\hline & Arrivals (\%) & Overnight stays (\%) \\
\cline { 2 - 3 } Cultural heritage destinations & 35.6 & 25.4 \\
Mountain destinations & 10.1 & 12.6 \\
Lake destinations & 6.0 & 7.2 \\
Seaside destinations & 21.5 & 30.8 \\
Watering destinations & 3.4 & 3.5 \\
Hills and other destinations & 4.0 & 3.8 \\
Other County Towns $^{(a)}$ & 2.1 & 1.6 \\
Other Municipalities $^{(a)}$ & 17.2 & 15.0 \\
Total & 100 & 100 \\
\hline
\end{tabular}

(a) not otherwise classified

Source: Istat 
Figure 2 draws a picture of tourism flows distribution across the 20 most visited provinces in Italy. Eleven of them are coastal provinces (i.e. they include at least one littoral municipality). Although for most of them the domestic share is the most relevant (Venice, Rome and Naples are exceptions), the international flows to these coastal provinces represent more than half of the overall international flows.

Figure 2. The twenty most visited provinces in 2011 (thousands of overnight stays).

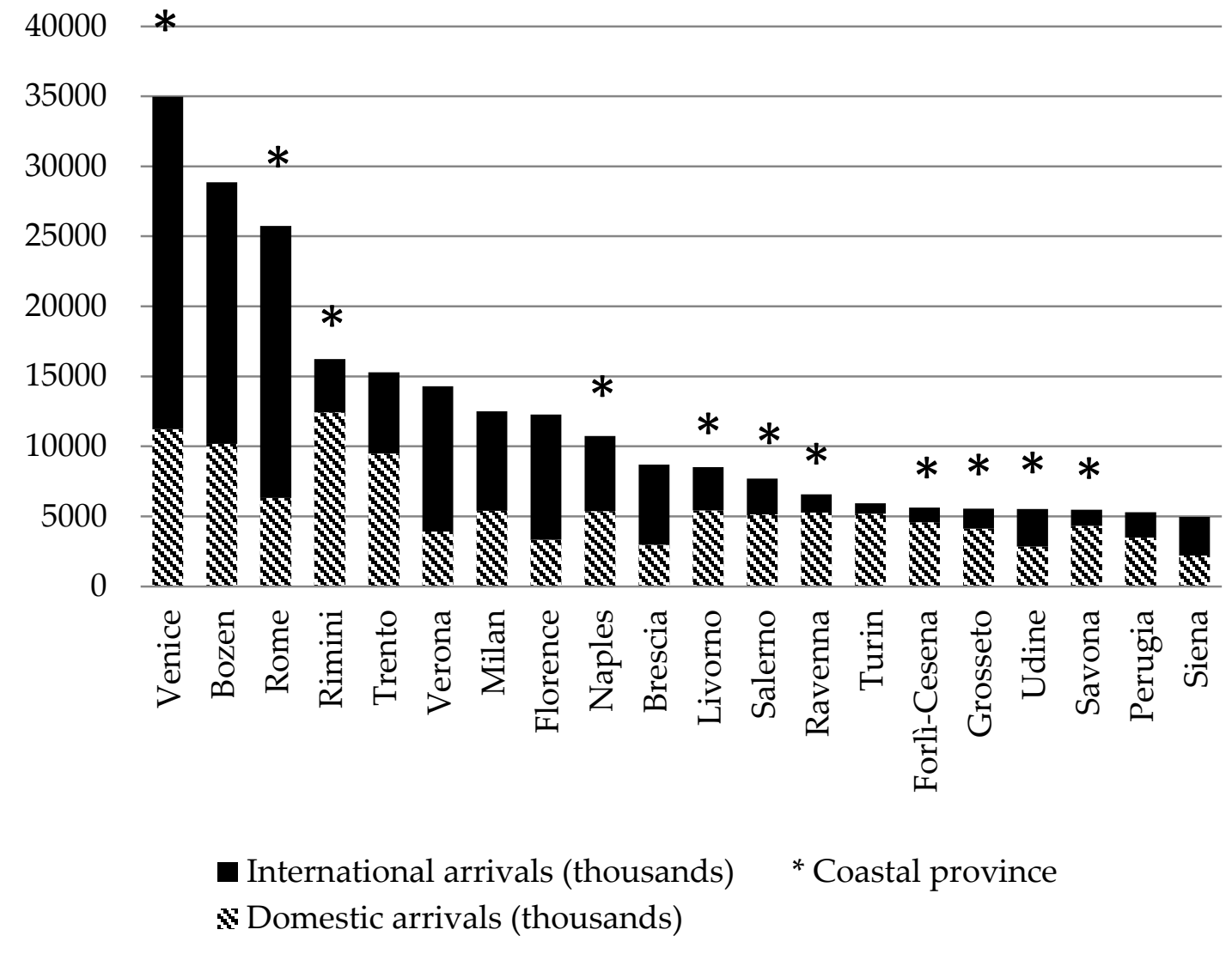

Source: Istat

3 The assessment of the economic impact of tourism certifications

Environmental accreditations and general quality certifications of tourism destinations have definitely entered the debate on site attractiveness and competitiveness, especially given the great emphasis conferred by newspapers and stakeholders. Yet, evidence on their effectiveness in affecting tourism performances is unclear. Many attempts in assessing the effectiveness of tourist site labels can be found in the literature mainly with regard to environmental and cultural quality certifications ${ }^{4}$, but heterogeneity in methods and scopes makes it difficult to draw reliable conclusions.

\footnotetext{
${ }^{4}$ Cultural destinations compete to attract tourist flows exactly like seaside destinations. Certifications are used by destinations to signal a cultural supply of high quality. The inscription in the World Heritage List of the UNESCO (WHL) is one of the most known destinations certification worldwide.
} 
In fact, the effectiveness of signaling can be assessed by looking at different outcomes (i.e. the variables on which the label is expected to exert some effect). Many studies have focused on the effect certifications have on people awareness and perception (e.g. recognition of signals, knowledge about label purposes), their motivation to visit places or their purchase intentions (Sparks et al., 2013; McKenna et al., 2011; Fairweather et al., 2005; Nelson and Botterill, 2002; Budeanu, 2007). Yet, these studies focus on consumer attitudes and mainly pertain to qualitative research fields, without providing estimates of economic effectiveness of signaling.

In order to narrow the focus of the analysis to economic evaluation of tourism labeling we undertook a systematic review of existing impact assessments specifically referring to changes in tourism demand and efficiency due to signaling. A number of search terms have been used including "certification", "signaling", "ecolabel", "Blue Flag", "impact", "tourism", "demand", "effectiveness". Search is performed within the main tourism journals such as Tourism Management, Tourism Economics, Journal of Travel Research, Annals of Tourism Research. A Gooogle Scholar search has also been run in order to identify published studies in other peer-reviewed journals as well as working papers, conference proceedings and official reports. Studies reporting qualitative evaluations have been excluded. To be included in this review, each study should indicate explicitly a) the kind of certification considered (cultural, environmental, etc.), b) the geographic focus (national, regional, sub-regional) of the evaluation, c) the outcome variable over which the change is expected (tourist arrivals, overnight stays, etc.), d) the quantitative method employed, e) the time period covered by the analysis, f) the data used, g) the estimates of the impact.

Twelve studies fulfill the above criteria. Four of them are working papers and two refer to other existing analyses (Cellini, 2011 comments Arezki et al., 2009 and Yang et al., 2010 while Yang and Lin, 2011 is a reply). Table 3 summarizes the key features of the selected works. Among those studies testing the effects on tourism flows, eight papers refer to cultural certifications (mainly inclusion into the UNESCO World Heritage Site list) and four to environmental certifications of beach destinations (mainly the Blue Flag list). Among the four studies referring to environmental signaling (all are seaside certifications), two of them focus on the Italian case, neither of the two have the explicit aim of assessing label impact (while the label awarding enters the models as a control variable). With regard to the estimated impact on tourist flows, in seven cases the impact was found to be positive, Cuccia et al. (2013) report a negative effect, and in the remaining four works no significant effect emerges. It is worth noting that when the empirical analysis takes advantage of geographically disaggregated data, environmental signaling of beaches shows a positive effect.

The present work places itself within this strand of the literature and is aimed at specifically estimating the effect of environmental accreditation of beaches on tourism flows inbound in Italy. While only two works have been found in the literature considering Blue Flag awarding as a control variable for tourism demand modeling, they exploit either geographically disaggregated data (Marrocu and Paci, 2013) or multiple year observations (Quintiliani, 2009). This study originally contributes to the literature by simultaneously exploiting a high geographic disaggregation of data and a relatively high number of periods. 
Table 3 Key studies on economic effectiveness of destinations certification, main features.

\begin{tabular}{cl}
\hline Type of certification & \multicolumn{1}{c}{ Study } \\
\hline \multirow{2}{*}{ Environmental } & Quintiliani (2009), Blackman et al. (2012), Marrocu and Paci (2013), \\
& Fuentes Medina et al. (2012) \\
Cultural & Yang et al. (2010), Cellini (2011), Yang and Lin (2011), Cuccia et al. \\
& (2013), Arezki et al. (2009), Cellini and Torrisi (2009), Lorenzini et al. \\
& (2011), Mazanec et al. (2007)
\end{tabular}

\section{Outcome variable}

Technical efficiency

New hotel investments

Tourism flows

GDP growth/Value Added generated from tourism
Fuentes Medina et al. (2012), Cuccia et al. (2013),

Blackman et al. (2012)

Marrocu and Paci (2013), Quintiliani (2009), Yang et al.( 2010), Cellini, (2011), Yang and Lin (2011), Cellini and Torrisi (2009), Lorenzini et al. (2011), Mazanec et al. (2007)

Arezki et al. (2009), Cellini and Torrisi (2009)

\begin{tabular}{|c|c|c|}
\hline \multicolumn{3}{|l|}{ Aim of the study } \\
\hline $\begin{array}{l}\text { Specifically aimed at impact } \\
\text { assessment }\end{array}$ & \multicolumn{2}{|c|}{$\begin{array}{l}\text { Yang et al. (2010), Cellini (2011), Yang and Lin (2011), Cuccia et al. } \\
\text { (2013), Blackman et al. (2012), Fuentes Medina et al.(2012), Lorenzini } \\
\text { et al. (2011) }\end{array}$} \\
\hline $\begin{array}{l}\text { Certification as a control } \\
\text { variable }\end{array}$ & \multicolumn{2}{|c|}{$\begin{array}{l}\text { Quintiliani (2009), Marrocu and Paci (2013), Arezki et al. (2009), } \\
\text { Cellini and Torrisi (2009), Mazanec et al. (2007) }\end{array}$} \\
\hline \multicolumn{3}{|l|}{ Geographic focus } \\
\hline $\begin{array}{l}\text { National } \\
\text { Regional }\end{array}$ & \multicolumn{2}{|c|}{ Arezki et al. (2009), Mazanec et al. (2007) } \\
\hline Sub-regional & \multicolumn{2}{|c|}{$\begin{array}{l}\text { Yang et al. (2010), Cellini (2011), Yang and Lin (2011), Marrocu and } \\
\text { Paci (2013), Blackman et al. (2012), Fuentes Medina et al.( 2012), } \\
\text { Lorenzini et al. (2011) }\end{array}$} \\
\hline \multicolumn{3}{|l|}{ Type of analysis } \\
\hline Cross section analysis & \multirow{2}{*}{\multicolumn{2}{|c|}{$\begin{array}{l}\text { Marrocu and Paci (2013), Cellini and Torrisi (2009), Lorenzini et } \\
\text { al.(2011), Mazanec et al. (2007) } \\
\text { Arezki et al.(2009), Fuentes Medina et al.(2012), Blackman et al. } \\
\text { (2012), Quintiliani (2009), Cuccia et al. (2013), Yang et al. (2010), Yang } \\
\text { and Lin (2011) }\end{array}$}} \\
\hline Longitudinal analysis & & \\
\hline Impact & Environmental & Cultural \\
\hline Positive & $\begin{array}{l}\text { Marrocu and Paci (2013), } \\
\text { Blackman et al.( 2012), Fuentes } \\
\text { Medina et al. (2012) }\end{array}$ & $\begin{array}{l}\text { Yang et al. (2010), Yang and Lin } \\
\text { (2011), Arezki et al. (2009), } \\
\text { Mazanec et al. (2007) }\end{array}$ \\
\hline Negative & & Cuccia et al. (2013) \\
\hline No effect & $\begin{array}{l}\text { Quintiliani (2009), Lorenzini et al. } \\
\text { (2011) }\end{array}$ & $\begin{array}{l}\text { Cellini ( 2011), Cellini and } \\
\text { Torrisi( 2009) }\end{array}$ \\
\hline
\end{tabular}

\section{$4 \quad$ Data and empirical specification}

In order to isolate the effect of environmental certification on international tourism flows to Italian coastal destinations, we model the main determinants of tourism 
demand exploiting panel data techniques, taking into account potential persistency effects.

As tourists' income and prices (at destination and in competing destinations) are the main determinants of tourism demand, we model tourism flows as a function of income and price factors and - following previous research in the field - we include a set of additional variables to account for non-economic pull effects ${ }^{5}$.

Information on foreign tourist flows comes from the frontier survey on inbound tourism in Italy conducted yearly by the Bank of Italy $(\mathrm{BI})^{6}$. The survey provides data on the number of foreign travelers who are leaving Italy (randomly selected and interviewed at frontier posts) and on the number of nights they spent in the country. Data are detailed up to the municipality level ${ }^{7}$.

Given the objective of assessing the impact of quality certification attributed to beaches, a high level of geographic disaggregation would be desirable for the analysis, but a trade-off with the availability of adequate control variables emerges. As a consequence, the province level has been chosen as the proper feasible geographic disaggregation. However, by virtue of the high level of geographic detail of BI data, the coastal tourism has been disentangled from the total provincial tourist flows. Even if the province is maintained as the unit of analysis, only tourism flows directed to costal destinations are considered. Thus, units of the analysis are 56 Italian coastal provinces. Since a number of administrative changes has occurred during the period covered by the present study, some adjustments were necessary in order to assure stability in geographic units across time $^{8}$ and the 2011 layout has been chosen as benchmark ${ }^{9}$.

Annual tourist arrivals and overnight stays $\left(Y_{i t}\right)$ in each coastal province are employed as indicators of tourism demand and explored as dependent variables in our models.

We consider per capita Gross Domestic Product $\left(G D P_{j t}\right)$ as proxy for disposable income of the $j$-th country of origin of international tourism to Italy. According to ISTAT and the Bank of Italy the most relevant international inbound flows are generated by Germany, France, USA, United Kingdom, Spain, Switzerland and Netherland (see Table A1 in the Appendix). Real GDP data are expressed at the purchasing power parity and are drawn from the World Bank database. Consumer Price Indices of Italian provinces $\left(C P I_{i t}\right)$ and of their main international competitors on seaside tourism (France, Greece, Croatia and Spain) account for tourism and substitute prices $\left(C P I_{k t}\right)$. Data come from Eurostat (national Harmonized Index of Consumer Prices) and ISTAT (province prices). Crude oil real price $\left(O I L_{t}\right)$ as published by the World Bank is a - admittedly rough - proxy for travel costs.

\footnotetext{
${ }^{5}$ Cf., inter al., the comprehensive review of existing studies on tourism demand modeling by Song and Li (2008), Marrocu and Paci (2013) and Massidda and Etzo (2012)

${ }^{6}$ Bank of Italy. Turismo internazionale dell'Italia.

7 The number of overnight stays in each municipality visited is recorded.

8 Six new provinces have been established and some municipalities changed their province affiliation, during the period covered by the present analysis. Detailed description of harmonization procedures adopted are available upon request from the authors.

${ }_{9}$ According to ISTAT, in 2011 Italy counted 645 coastal municipalities, pertaining to 56 coastal provinces.
} 
Two variables accounting for destination attributes are included. The first is a composite indicator of the quality of life $\left(Q O L_{i t}\right)$ estimated at the province level ${ }^{10}$. It synthetizes assessments of living standards, business and labor conditions, services and environment, delinquency, population and leisure. The second is a measure of accessibility (by road, rail and air) as estimated by ESPON $\left(R O A D_{i}, R A I L i, A I R i\right)^{11}$.

With regard to our variable of interest, data on the Blue Flag attribution to coastal municipalities are published every year on the official web site of the Blue Flag Program ${ }^{12}$. The certification achievement $\left(B F_{i t}\right)$ enters our model alternatively as a dummy variable for the presence of at least a Blue Flag winner within the $i$-th province or as a numeric variable equal to the number of municipalities who achieved a Blue Flag within the province $i$ in year $t$.

The number of littoral municipalities pertaining to the $i$-th province or their surface areas in $\mathrm{km}^{2}$ (Surfacei) serves the purpose of accounting for different geographic dimensions. The analysis is conducted on a panel of 728 observations, consisting in annual data from 2000 to 2012 on the 56 coastal provinces.

As a preliminary analysis we estimate a static specification of tourism demand expressed as follows:

$$
\begin{gathered}
Y_{i t}=\beta_{0}+\beta_{1} B F_{i t}+\beta_{2} B F_{i, t-1},+\beta_{3} G D P_{j t}+\beta_{4} C P I_{k t}+\beta_{5} C P I_{i t}+\beta_{6} O I L_{t}+\beta_{7} A I R_{i}+ \\
\beta_{8} Q O L_{i t}+\beta_{9} \text { Surface }_{i}+\varepsilon_{i t}
\end{gathered}
$$

where the error term $\varepsilon_{i t}$ consists of two terms, namely a province specific component, which does not vary over time $\left(u_{i}\right)$, and a white noise error term $\left(v_{i t}\right)$ :

$$
\varepsilon_{i t}=u_{i}+v_{i t}
$$

The Fixed Effect (FE) and the Random Effect (RE) estimators can be used to model individual heterogeneity. The FE estimator treats the idiosyncratic effects as unknown province-specific parameters to be estimated, while the RE estimator treats them as random variables which are assumed to have zero correlation with the other explanatory variables. The appropriateness of these estimators will be explored.

As widely discussed by Morley (1998), tourism demand is likely to be affected both by reputation and persistency effects. On the one hand, previous tourism flows have the effect of increasing information on destinations, thereby they potentially affect the current level of tourism to the same destination. On the other hand, habits might induce tourists to not vary their destinations over time. Of course static models fail to capture these patterns.

In order to account for the influence of past decisions on current tourists' decisions, we estimate also a dynamic specification and test the impact of the lagged dependent variable $\left(Y_{i, t-1}\right)$ :

\footnotetext{
10 Yearly estimates are published by Il sole 24 ore since 1989 .

${ }^{11}$ Province accessibility indicators refer to the year 2006 (http://www.espon.eu/).

${ }^{12}$ http://www.BlueFlag.org/ and http://www.bandierablu.org/.
} 
(3) $Y_{i t}=\gamma_{0}+\gamma_{1} B F_{i t}+\gamma_{2} B F_{i, t-1}+\gamma_{3} G D P_{j t}+\gamma_{4} C P I_{k t}+\gamma_{5} C P I_{i t}+\gamma_{6} O I L_{t}+\gamma_{7} A I R_{i}+$ $\gamma_{8} Q O L_{i t}+\gamma_{9}$ Surface $_{i}+\gamma_{10} Y_{i, t-1}+\varepsilon_{i t}$

The system GMM estimator by Arellano and Bover (1995) and Blundell and Bond (1998) is employed. This allows to account for individual effects and to control for the endogeneity induced by the introduction of the lagged dependent variable.

All the variables are in natural logarithms (except dummies) and coefficients can be interpreted in terms of elasticities.

The empirical analysis proceeds as follows: the static model (1) and the dynamic model (2) are estimated considering alternatively the binary indicator for the Blue Flag and the number of Blue Flags awarded. The Blue Flags effectiveness is investigated both with regard to arrivals and to overnight stays (the latter set of results is reported in the Appendix). Finally, the dynamic model is also estimated employing total tourism flows to the province (coastal and non-coastal) as dependent variable.

\section{$5 \quad$ Econometric results}

\section{The impact of beach ecolabels on international seaside tourism.}

In the preliminary phases of the analysis we estimate the static version of the demand model (equation 1) using BI data on inbound flows to Italian coastal destinations. Estimation results for the Pooled OLS estimator, the FE estimator and the RE estimator are shown in Table 4 for comparison. The number of foreign arrivals to coastal municipalities is the dependent variable.

Table 4. Static model results, Pooled OLS, FE and RE estimates.

\begin{tabular}{lccc}
\hline & Pooled OLS & FE & RE \\
\hline Blue Flag - dummy & 0.276 & 0.039 & 0.048 \\
Blue Flag - dummy (-1) & $0.411^{* *}$ & $0.098^{* *}$ & $0.107^{* *}$ \\
Coastal municipality surface $\left(\mathrm{km}^{2}\right)$ & $0.488^{* * *}$ & & $0.392^{* *}$ \\
Province Consumer Price Index & $-2.895^{* *}$ & -0.810 & $-0.838^{* *}$ \\
Accessibility by air (Espon Index) & $0.043^{* * *}$ & & $0.046^{* *}$ \\
Province Quality of Life & $2.766^{* *}$ & 0.338 & $0.395^{*}$ \\
GDP per capita - Germany (PPP) & 2.830 & $1.105^{*}$ & $1.114^{*}$ \\
Constant & $-28.991^{*}$ & 1.305 & $-5.272^{*}$ \\
\hline Obs. & & & \\
F test & 672 & & \\
Breusch and Pagan & Prob>F=0.000 & \\
Hausman test & Prob>chibar ${ }^{2}=0.000$ & & \\
\hline
\end{tabular}

Notes: Dependent variable: Ln of foreign arrivals to coastal municipalities.

All the variables are log transformed, except dummies.

Stars denote $p$-values as follows: ${ }^{* *} 1 \%,{ }^{* *} 5 \%,{ }^{*} 10 \%$

Robust estimates.

Significant individual effects emerge from the $\mathrm{F}$ test performed on the FE model and from the Breush and Pargan test on the RE model (the absence of significant individual 
heterogeneity is rejected in both cases). Yet, results for the OLS pooled specification are reported for completeness ${ }^{13}$.

No correlation between the idiosyncratic effects and the explanatory variables emerges according to the Hausman test, ${ }^{14}$ suggesting RE estimates can be preferred.

According to Table 4 sign and magnitude of the estimated coefficients are consistent with a priori expectations and in line with previous results in the literature (e.g. Garin-Munoz and Montero-Martin, 2007, for a review of estimates of price and income elasticities from existing empirical studies on international tourism demand for Spain). With regard to the BF indicator, the lagged label dummy has a significant positive coefficient, while no significant effect is found for the current period (a more detailed discussion will follow).

Table 5. Dynamic model results, Blue Flag binary indicator (Column 1) and numeric indicator (Column 2) employed.

\begin{tabular}{|c|c|c|}
\hline & \multicolumn{2}{|c|}{ System GMM } \\
\hline & Column 1 & Column 2 \\
\hline Arrivals (-1) & $0.502^{* * *}$ & $0.531^{* * *}$ \\
\hline Arrivals $(-2)$ & $0.279^{* * *}$ & $0.276^{* * *}$ \\
\hline Blue Flag - dummy & 0.045 & \\
\hline Blue Flag - dummy (-1) & $0.137^{* *}$ & \\
\hline Blue Flag - number & & -8.055 \\
\hline Blue Flag - number (-1) & & 1.863 \\
\hline Coastal municipality surface $(\mathrm{km} 2)$ & 0.119 & \\
\hline Province Consumer Price Index & $-2.690^{* * *}$ & $-2.478^{* * *}$ \\
\hline Accessibility by air (Espon Index) & 0.196 & -0.005 \\
\hline Province Quality of life Index & $0.960^{* * *}$ & $0.895^{* * *}$ \\
\hline German GDP per capita (PPP) & $3.276^{* * *}$ & $3.189^{* * *}$ \\
\hline Constant & $-26.904^{* * *}$ & $-24.651^{* * *}$ \\
\hline Obs. & 616 & 616 \\
\hline Nr. of instruments & 27 & 27 \\
\hline ABond AR(1) & Prob $>z=0.004$ & Prob $>z=0.001$ \\
\hline ABond AR(2) & Prob $>z=0.099$ & Prob $>z=0.108$ \\
\hline Sargan & Prob $>$ chi $^{2}=0.1417$ & Prob $>$ chi $^{2}=0.098$ \\
\hline
\end{tabular}

Notes: Dependent variable: Ln of foreign arrivals to coastal municipalities.

All the variables are log transformed, except BF indicators.

Stars denote $\mathrm{p}$-values as follows: ${ }^{* *} 1 \%,{ }^{* *} 5 \%,{ }^{*} 10 \%$

Robust estimates.

${ }^{13}$ The pooled OLS estimator provides biased results in presence of significant individual effects.

14 The null hypothesis of non-systematic difference between FE and RE coefficients is not rejected suggesting no correlation between the explanatory variables and the individual effects. Thus, the RE estimator can be employed without fear of producing biased estimates. In fact, the RE estimator, if consistent, produces more efficient estimates, since it exploits variation both within and between individuals. 
Yet, tourism demand is likely to be affected by dynamic patterns due to persistency and reputation effects. A static model fails to capture those patterns and risk to provide unreliable estimates. Table 5 shows the estimated coefficients of the dynamic specification (equation 2).

Column 1 in Table 5Table 5 shows results for the model including the dummy variable for the presence of at least one Blue Flag in the province, while Column 2 reports results for the model where the number of Blue Flags per province is employed as regressor ${ }^{15}$. The natural logarithm of arrivals is the dependent variable.

Post-estimation tests reveal an overall satisfactory performance of the econometric model. The Arellano Bond test shows no serial autocorrelation of order two in the first differenced errors. Moreover, the failure to reject the null hypothesis of the Sargan test of over-identifying restriction confirms no evidence of misspecified instruments.

As expected, significant positive coefficients of the two lags of the dependent variable show evidence of strong persistency in tourism demand and prove the need of a dynamic specification of the model. According to our results, more than $70 \%$ of the variability in international tourism flows to Italy can be attributed to the past, although this specification does not allow to isolate habits from reputation effects.

With regard to the economic determinants of international tourism demand, a positive elasticity is estimated for German per capita GDP. Since Germany is by far the most important generating country of international tourism flows to Italy (Table A1 in the Appendix), its GDP has been considered as a proxy for the income variable entering the international demand for tourism in Italian coasts. Moreover, while none of the substitute prices are statistically significant, prices at destination negatively affect tourism demand. Thus, consistently with the economic theory and with previous empirical results, the international demand for tourism directed to Italian littoral destinations proves to be responsive to price variability and heavily dependent on the economic situation of the main generating country.

With regard to the supply side, the quality of life at destination synthetizes multiple dimensions of province attractiveness such as the level of public security, the availability of recreational attractions, and the climate. According to our estimates, these factors play a relevant role in attracting tourists. However, the degree of potential accessibility (by air, road and rail ${ }^{16}$ ) and the travel costs are not statistically relevant in determining tourist demand.

Finally, overall geographic dimension (in $\mathrm{km}^{2}$ ) of coastal municipalities belonging to each province has been included in the model to account for the size effect, which is positive and significant.

15 The number of Blue Flags is deflated by the surface of coastal municipalities in the province (in $\mathrm{km}^{2}$ ).

16 The three indicators have been tested alternatively. Moreover a synthetic indicator of overall accessibility has been obtained by extracting the first latent component from the three original indicators through a principal component analysis. None of the four indicators proved to be statistically significant in the model. 
Once all these factors are controlled for, the lagged dummy variable for the Blue Flag achievement turns out to be significant and positive, suggesting that the accreditation of the province at time $t$ plays a role in tourism decisions referred to time $t+1$. According to this result, the ecolabel enters the tourists' decision process by providing synthetic information on the quality of coastal destinations. Significance of the lagged label indicator might depend on the timing of the decision process. Blue Flag accreditations are published every year at the beginning of the summer season when most of the consumers - particularly international ones - have already set their plans for vacations. Thus, current tourists' decisions are very likely to be based on information referred to the previous season.

Column 2 in Table 5 reports results from the estimation of equation 2, where the (normalized) number of ecolabels per province is employed instead of the dummy for the achievement of at least one signal. All the estimates are quite similar to Column 1, while the ecolabel coefficient is not statistically significant. This means that the presence of at least one environmental accreditation in the area makes the difference for the tourists' choices, while the number of accreditation is not really relevant. Tourism flows significantly differ among province with or without environmental signals, while they do not significantly vary according to the number of signals achieved.

The same analysis is performed using the number of overnight stays as dependent variable, and again the binary and the numeric indicator are included alternatively. Estimates are reported in the Appendix (Table A1 and Table A2 summarize results for the static and the dynamic model respectively). Results are similar to those in Table 5. The achievement of the Blue Flag increases the number of overnight stays in the province for the following season of about $15 \%$.

\section{The impact of beach ecolabels on the overall inbound tourism.}

In order to compare our results with existing studies based on regional or county data (Quintiliani, 2009, Marrocu and Paci, 2013), we estimate model 2 on the overall inbound tourism to Italian coastal provinces, irrespective of its seaside/non-seaside nature. Differently from the previous estimations where the tourism flows to coastal municipalities have been disentangled from the total, here overall international arrivals to the province are used as dependent variable.

Several Italian coastal provinces attract tourists for their littoral destinations and for seaside vacations, but also for cultural and natural attractions. Provinces with a strong cultural tourism component are likely to be only slightly affected by environmental accreditations of seaside places.

It is worth noting that these cases constitute a high share of the total inbound tourism (this is the case of Venice, Rome, Naples and many other provinces). As a consequence, we expect that the inclusion of non-seaside travelers in our analysis would weaken our results on the effectiveness of ecolabels. In fact, the estimates reported in Table 66 confirm the expectation and show no effect of the Blue Flags on the overall tourism flows towards the province ${ }^{17}$.

\footnotetext{
${ }^{17}$ To test the robustness of our findings, we estimate model (2) on non-seaside inbound arrivals to Italian coastal province (i.e. international tourists directed to non-littoral municipalities). As
} 
Table 6 Dynamic model results, overall inbound tourism to Italian coastal province.

\begin{tabular}{lc}
\hline & System GMM \\
\hline Arrivals (-1) & $0.623^{* * *}$ \\
Arrivals (-2) & $0.230^{* * *}$ \\
Blue Flag - dummy & -0.022 \\
Blue Flag - dummy (-1) & $0.029^{*}$ \\
Coastal municipality surface (km2) & $0.435^{* *}$ \\
Province Consumer Price Index & $-1.817^{* * *}$ \\
Accessibility by air (Espon Index) & $0.008^{* *}$ \\
Province Quality of life Index & $0.577^{* * *}$ \\
German GDP per capita (PPP) & $1.835^{* * *}$ \\
Constant & $-15.948^{* * *}$
\end{tabular}

\begin{tabular}{|c|c|c|}
\hline Obs. & & 616 \\
\hline Nr. of instruments & & 27 \\
\hline ABond AR(1) & \multicolumn{2}{|c|}{ Prob $>z=0.002$} \\
\hline ABond AR(2) & \multicolumn{2}{|c|}{ Prob $>z=0.087$} \\
\hline Sargan & Prob $>$ chi $^{2}=$ & 0.000 \\
\hline
\end{tabular}

Notes: Dependent variable: Ln of total arrivals to coastal province.

All the variables are log transformed, except dummies.

Stars denote $p$-values as follows: ${ }^{* *} 1 \%,{ }^{* *} 5 \%,{ }^{*} 10 \%$

Robust estimates.

Our analysis confirms that beach quality certifications have a role in determining foreign tourists' choices among seaside destinations. Foreign arrivals are influenced by the environmental quality of the destination province, as proxied by the achievement of a Blue Flag in the previous year. The signal effectiveness in attracting tourists is significant for seaside tourists' arrivals but not for the overall tourist flow.

A high geographic detail in data on arrivals allows to capture a seaside-specific phenomenon, while the use of heavily aggregated data might explain the small or not significant effect, as reported in the literature (Marrocu and Paci, 2013; Quintiliani, 2009).

In fact, signaling policies address specific market segments: the Blue Flag Program addresses seaside tourism, the World Heritage Program addresses cultural tourism, etc. Although segments are often overlapping (e.g. the same travel can have different purposes), the opportunity of observing each segment separately permits to properly capture its patterns. With regard to the seaside tourism, geographic allocation of arrivals can be employed to detect the beach and sun segment and the stays in coastal municipalities identify and isolate seaside tourism. The case of cultural tourism is less easily detectable. Sometimes the destination chosen for the stay by the tourist is not an adequate indicator of the kind of tourist he is, mainly in areas where different tourist

expected the Blue Flag binary indicator has no effect on international non-seaside arrivals (P-values for the current and lagged coefficients are 0.215 and 0.184 respectively). 
attractions can be found. Therefore it can be difficult to focus on those tourists to whom the signaling policy is targeted, and the estimation of the impact might be compromised.

\section{Conclusions}

This paper contributes to the literature on quality certification in tourism. While existing research mostly pertains to quality evaluation, we exploit quantitative methods to focus on economic effectiveness of destinations' labels. The analysis focuses on beach environmental certifications (Blue Flags awards) and their effectiveness in attracting foreign tourists.

By exploiting high geographic disaggregation in the data on arrivals and panel data techniques, we model the international demand for tourism in Italian coastal destinations. Having controlled for economic and non-economic factors, the quality certification achieved by the province during the previous year has a positive effect on the current inbound flows. According to our results, quality certifications help to fill the information gap on destinations and therefore can affect foreign tourist decisions positively. The lag might be explained by the timing of the international tourists' decision process, which likely precedes the public notification of the labels for the current season. In a policy perspective, this suggests that the Blue Flag data are released too late in the year to influence the current decision of foreign tourists. Moreover, while the presence of at least one signal within the area is effective in attracting arrivals, no significant difference has been found among destinations with different signal strength. It is worth noting that focusing on the proper share of tourism flows is a key factor in the assessment of labeling effectiveness, particularly in Italy, where in the same areas many different tourist attractions (cultural, natural, etc.) exist, and tourists' geographic distribution often is ineffective to detect alternative market segments.

Since the labeling policy considered is exclusively targeted at beaches, it is expected to affect consumption choices of seaside tourists. The high geographic detail in the data employed for the analysis allows to focus exclusively on them and a positive impact was found. When the analysis was replicated on the overall province inbound tourism, irrespective of its specific destination, no impact emerged. Thus, the significant effect exerted by the label on seaside tourists is hidden by the action of other factors affecting non-seaside tourists.

Finally, the econometric analysis developed in this study offers clear evidence about the effectiveness of beach quality certification in attracting seaside foreign tourists. This result is of great relevance for policymakers and stakeholders, who bear the costs of fulfilling the standards required for certifications. Information on the economic returns of quality standard achievement is essential. For this reason, according to data availability, further investigation on ecolabel impact on domestic tourism would be also desirable. 


\section{Appendix A}

Figure A 1. Geographic distribution of the Blue Flags among Italian coastal provinces, years 2000-2012

Year 2000

Year 2002

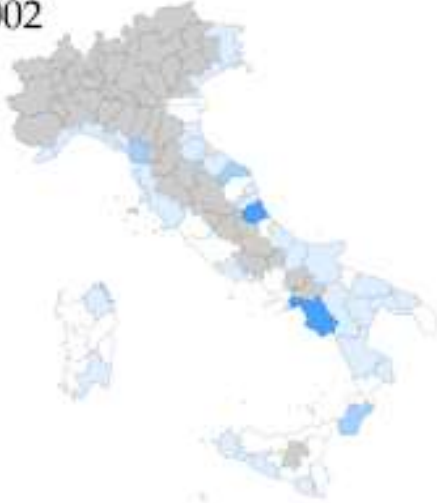

Year 2004

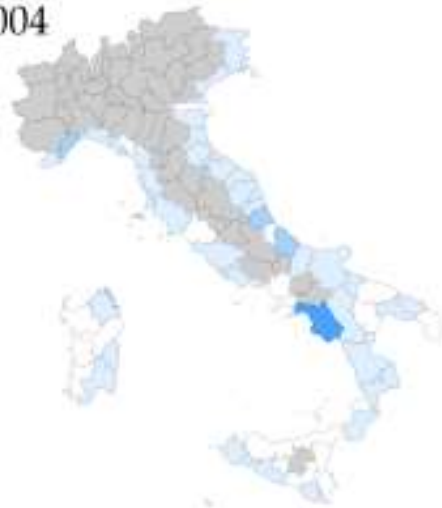

Year 2001

Year 2003

Year 2005

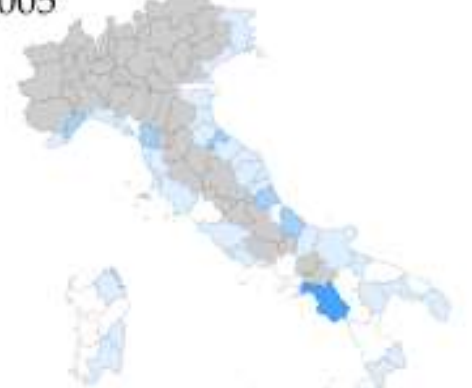


Year 2006

Year 2008

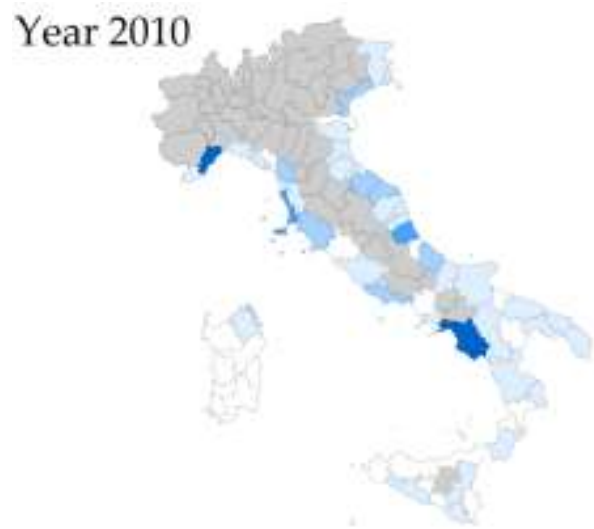

Year 2007
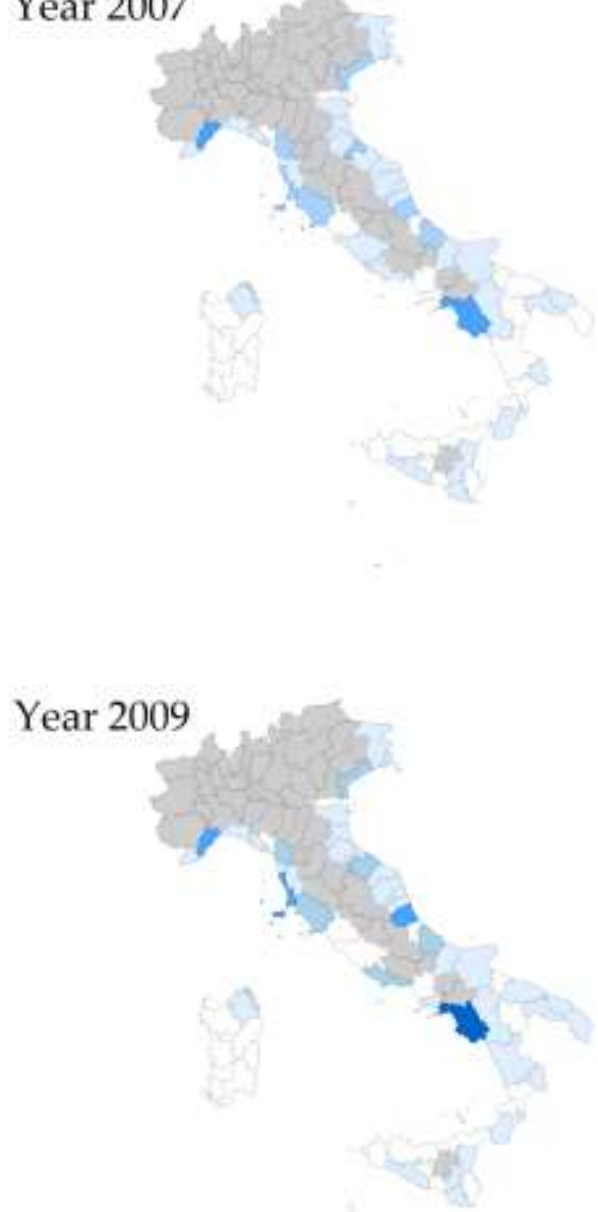

Year 2011

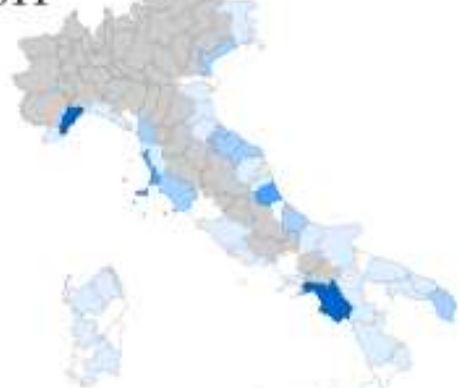




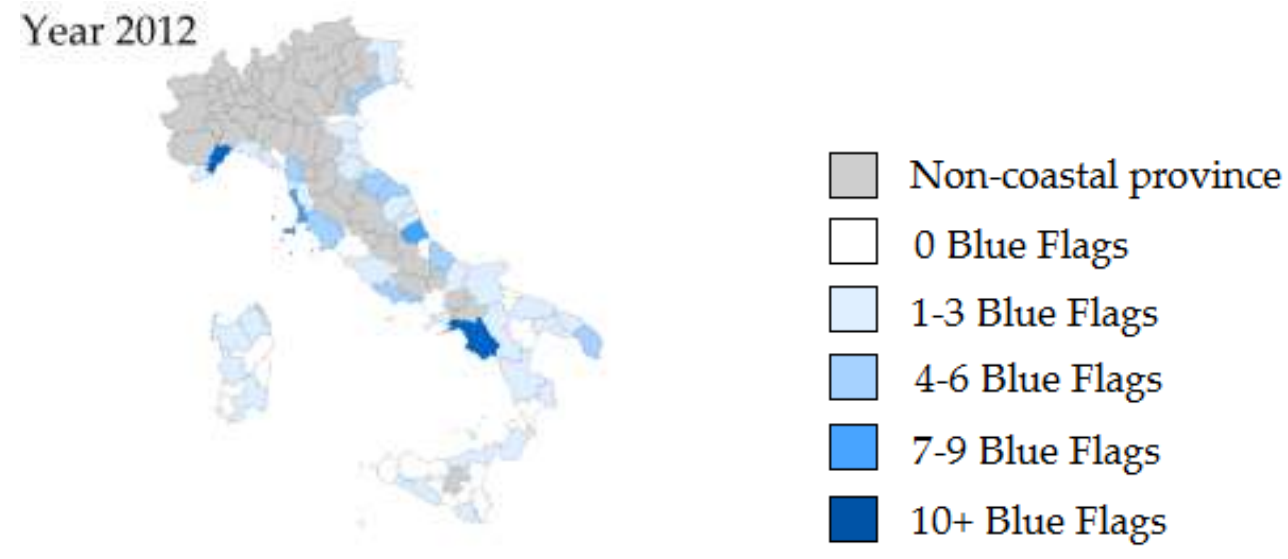

Table A 1. International tourist flows (first ten generating countries), 2012

\begin{tabular}{lccc}
\hline & $\begin{array}{c}\text { Overnight stays } \\
\text { (thousands) }\end{array}$ & $\begin{array}{c}\text { Arrivals } \\
\text { (thousands) }\end{array}$ & $\begin{array}{c}\text { Expenditure } \\
\text { (million } € \text { ) }\end{array}$ \\
\hline Germany & 62015 & 11713 & 53 \\
France & 31919 & 1026 & 2875 \\
USA & 28124 & 3076 & 3603 \\
United Kingdom & 23531 & 366 & 245 \\
Spain & 16563 & 2638 & 1239 \\
Switzerland & 14034 & 13166 & 2012 \\
Netherland & 12896 & 1927 & 1051 \\
Poland & 9324 & 154 & 685 \\
Austria & 1404 & 6949 & 1459 \\
Slovenia & 492 & 4193 & 205 \\
\hline
\end{tabular}

Source: Bank of Italy 
Table A 2. Static model results, Pooled OLS, FE and RE estimates. Dependent variable: Ln of overnight stays at coastal municipalities.

\begin{tabular}{lccl}
\hline & Pooled OLS (1) & FE(2) & RE(3) \\
\hline Blue Flag - dummy & $0.296^{*}$ & 0.041 & 0.054 \\
Blue Flag - dummy (-1) & $0.439^{* * *}$ & $0.166^{* * *}$ & $0.177^{* * *}$ \\
Coastal municipality surface $\left(\mathrm{km}^{2}\right)$ & $0.001^{* * *}$ & - & $0.001^{* * *}$ \\
Province Consumer Price Index & $-2.807^{* * *}$ & $-1.143^{* *}$ & $-1.176^{* *}$ \\
Accessibility by air (Espon Index) & $0.039^{* * *}$ & - & $0.040^{* * *}$ \\
Province Quality of Life & $0.865^{* *}$ & 0.332 & 0.368 \\
GDP per capita - Germany (PPP) & $2.751^{*}$ & 0.807 & 0.831 \\
Constant & -11.978 & 8.249 & 3.897 \\
\hline \multicolumn{5}{l}{} \\
Obs. & 672 & & \\
F test & Prob>F=0.000 & \\
Breusch and Pagan & Prob>chibar2=0.000 & \\
Hausman test & Prob>chi2=0.3700 & \\
\hline
\end{tabular}

Notes: Dependent variable: Ln of night stays at coastal municipalities.

All the variables are log transformed, except dummies.

Stars denote $p$-values as follows: ${ }^{* *} 1 \%,{ }^{*} 5 \%,{ }^{*} 10 \%$.

Robust estimates. 
Table A3. Dynamic model results, Blue Flag binary indicator (Column 1) and numeric indicator (Column 2) employed. Dependent variable: Ln of total overnight stays at coastal municipalities.

\begin{tabular}{|c|c|c|}
\hline & \multicolumn{2}{|c|}{ System GMM } \\
\hline & Column 1 & Column 2 \\
\hline Overnight stays (-1) & $0.380^{* * *}$ & $0.439^{* * *}$ \\
\hline Overnight stays (-2) & $0.341^{* * *}$ & $0.350^{* * *}$ \\
\hline Blue Flag - dummy & 0.162 & \\
\hline Blue Flag - dummy (-1) & $0.150^{* *}$ & \\
\hline Blue Flag - number & & -8.219 \\
\hline Blue Flag - number $(-1)$ & & 4.408 \\
\hline Coastal municipality surface (km2) & 0.201 & \\
\hline Province Consumer Price Index & $-2.521^{* * *}$ & $-2.376^{* *}$ \\
\hline Accessibility by air (Espon Index) & 0.011 & 0.007 \\
\hline Province Quality of life Index & 0.627 & $0.708^{*}$ \\
\hline German GDP per capita (PPP) & $2.812^{* * *}$ & $2.868^{* * *}$ \\
\hline Constant & $-20.124^{* *}$ & $-20.939^{* *}$ \\
\hline Obs. & 616 & 616 \\
\hline Nr. of instruments & 27 & 27 \\
\hline ABond AR(1) & Prob $>\mathrm{z}=0.008$ & Prob $>\mathrm{z}=0.005$ \\
\hline ABond AR(2) & Prob $>\mathrm{z}=0.097$ & Prob $>z=0.128$ \\
\hline Sargan & Prob $>$ chi $^{2}=0.065$ & Prob $>$ chi $^{2}=0.046$ \\
\hline
\end{tabular}

Notes: Dependent variable: Ln of night stays at coastal municipalities.

All the variables are log transformed, except BF indicators.

Stars denote $\mathrm{p}$-values as follows: ${ }^{* *} 1 \%,{ }^{* *} 5 \%,{ }^{*} 10 \%$.

Robust estimates.

Column 1 shows results for the model including the dummy variable for the presence of at least one Blue Flag in the province. Column 2 reports results for the model where the number of Blue Flags per province is employed as regressor. 


\section{References}

Arellano, M. \& Bover, O. (1995). Another look at the instrumental variable estimation of error-components models. Journal of Econometrics, 68, 29-51.

Arezki, R., Cherif, R., \& Piotrowski, J. (2009). Tourism specialization and economic development: Evidence from the UNESCO World Heritage List. (vols. 2009-2176) International Monetary Fund.

Blackman, A., Naranjo, M.A., Robalino, J., Alpízar, F., \& Rivera, F. (2012). Does Tourism Eco-Certification Pay? Costa Rica's Blue Flag Program (Rep. No. EfD DP 12-13). Environment for Development.

Blundell, R. \& Bond, S. (1998). Initial conditions and moment restrictions in dynamic panel data models. Journal of econometrics, 87, 115-143.

Buckley, R. (2004). The effects of World Heritage listing on tourism to Australian national parks. Journal of Sustainable Tourism, 12, 70-84.

Budeanu, A. (2007). Sustainable tourist behaviour -a discussion of opportunities for change. International Journal of Consumer Studies, 31, 499-508.

Cellini, R. (2011). Is UNESCO recognition effective in fostering tourism? A comment on Yang, Lin and Han. Tourism Management, 32, 452-454.

Cellini, R. \& Torrisi, G. (2009). The regional public spending for tourism in Italy: an empirical analysis (Rep. No. Paper No. 16917).

Cuccia, T., Guccio, C., \& Rizzo, I. (2013). Does Unesco inscription affect the performance of tourism destinations? A regional perspective the Association for Cultural Economics International.

Fairweather, J.R., Maslin, C., \& Simmons, D.G. (2005). Environmental values and response to ecolabels among international visitors to New Zealand. Journal of Sustainable Tourism, 13, 82-98.

Garin-Munoz, T. \& Montero-Martin, L.F. (2007). Tourism in the Balearic Islands: A dynamic model for international demand using panel data. Tourism Management, 28, 1224-1235.

Lorenzini, E., Calzati, V., \& Giudici, P. (2011). Territorial brands for tourism development: A statistical analysis on the Marche Region. Annals of Tourism Research, 38, 540-560.

Marrocu, E. \& Paci, R. (2013). Different tourists to different destinations. Tourism Management, 39, 71-83.

Massidda, C. \& Etzo, I. (2012). The determinants of Italian domestic tourism: A panel data analysis. Tourism Management, 33, 603-610.

Mazanec, J. A., Wöber, K., \& Zins, A. H. (2007). Tourism destination competitiveness: from definition to explanation?. Journal of Travel Research, 46, 86-95.

McKenna, J., Williams, A.T., \& Cooper, J. A. (2011). Blue Flag or Red Herring: Do beach awards encourage the public to visit beaches? Tourism Management, 32, 576-588.

Medina, L.F., Gomez, I.G., \& Marrero, S.M. (2012). Measuring efficiency of sun \& beach tourism destinations. Annals of Tourism Research, 39, 1248-1251.

Morley, C. L. (1998). A dynamic international demand model. Annals of Tourism Research, 25, $70-84$.

Nelson, C. \& Botterill, D. (2002). Evaluating the contribution of beach quality awards to the local tourism industry in Wales - Green Coast Award. Ocean \& coastal management, 45, 157-170.

Quintiliani, F. (2009). International tourism in the coastal regions of five mediterranean countries. Tourism Analysis, 14, 353-373.

Song, H. \& Li, G. (2008). Tourism demand modelling and forecasting - A review of recent research. Tourism Management, 29, 203-220. 
Sparks, B. A., Perkins, H. E., \& Buckley, R. (2013). Online travel reviews as persuasive communication: The effects of content type, source, and certification logos on consumer behavior. Tourism Management, 39, 1-9.

WTTC (2012). Economic Impact 2012 - World Travel \& Tourism Council, World Travel Tourism Council, London

WTTC (2013). Economic Impact 2013 - World Travel \& Tourism Council, World Travel Tourism Council, London

Yang, C.H. \& Lin, H.L. (2011). Is UNESCO recognition effective in fostering tourism? A comment on Yang, Lin and Han: reply. Tourism Management, 32, 455-456.

Yang, C.H., Lin, H.L., \& Han, C.C. (2010). Analysis of international tourist arrivals in China: The role of World Heritage Sites. Tourism Management, 31, 827-837. 


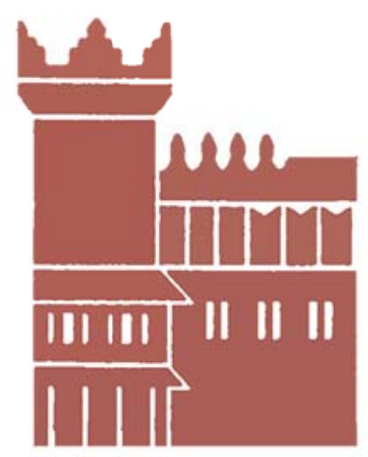

Alma Mater Studiorum - Università di Bologna DEPARTMENT OF ECONOMICS

Strada Maggiore 45

40125 Bologna - Italy

Tel. +39051 2092604

Fax +390512092664

http://www.dse.unibo.it 